\title{
La muerte de Alonso Quijano, un adiós literario ${ }^{1}$
}

\author{
JORDI AlADRO* \\ "cuando algún pintor quiere salir famoso en su arte, procura imitar \\ los originales de los más únicos pintores que sabe" $(\mathrm{I}, \mathrm{XXV})^{2}$ \\ "Caballero andante he de morir" (II,I), \\ "tal será nuestra muerte como hubiera sido nuestra vida"
}

(Preparatio ad mortem, Erasmo)

El capítulo final de El Quijote: "De como Don Quijote cayó malo, y del testamento que hizo, y su muerte" ha recibido amplia atención y atenta lectura, tanto simbólica como moral. Veamos algunos de los más destacados ejemplos: a Thomas Mann no le gustó como se muere Alonso Quijano, le parece una muerte "pálida" 3 ; Borges encontraba abrupta la transición entre la locura y la cordura en el hidalgo manchego 4 ; Américo Castro vio la muerte de don Quijote como mors post errorem, "fórmula de expiación tan grata a Cervantes"5; para Otis H. Green es una muerte "post melancholiam"6. Para Juan Bautista Avalle-Arce don Quijote "vuelve a sus cabales para adoptar la identidad

\footnotetext{
* University of California, Santa Cruz.

1. En forma muy reducida este trabajo fue presentado en XI Coloquio Internacional de la Asociación de Cervantistas con el título La muerte de Alonso Quijano, la última imitación de Don Quijote, celebrado en Seúl entre el 17 y el 20 de noviembre de 2004.

2. Cito por la edición de Rico, Francisco, Don Quijote de la Mancha, Barcelona, Crítica, 1998. Todos los subrayados son míos.

3. MANN, Thomas, Leiden und Grösse der Meister, Berlín, S. Fischer, 1935, p. 234.

4. BorGES, Jorge Luis, "Notas sobre el Quijote", Realidad 2, 1947, pp. 234-236.

5. CAstro, Américo, El pensamiento de Cervantes, Barcelona, Noguer, 1972, p. 133.

6. GREEN, Otis H. , "Melancholy and Death in Cervantes", Hispanic Studies in Honor of Nicholson B. Adams, Chapel Hill: University of North Carolina Press, 1966, p. 55.
} 
con que quiere enfrentar a su creador" ; Joaquín Casalduero cree que "Don Quijote adoctrina hasta su último momento, cuando encuentra la lección mejor, la de su muerte" ; para Henryk Ziomek "el hidalgo manchego muere, como haya vivido, valerosa, estoica y cristianamente" ; James Iffland la ve como "la reintegración de su protagonista, ya cuerdo, a la sociedad civil y al marco del ritual eclesiástico." 10 Luis Andrés Murillo la interpreta como un sacrificio: "Quixano dies in this exemplary manner so that the fame of Don Quixote can live on intact in its proper sphere, the world of fiction"11 ; de "muerte ejemplar" la califica Alberto Sánchez ${ }^{12}$. Recientemente, Edgardo Rodríguez Juliá hasta ha llegado afirmar que se trata de una "crueldad de Cervantes novelista, el consuelo de su neurastenia."13 Ahora bien, todas las lecturas/interpretaciones de estos excelentes investigadores que tanto han aportado al conocimiento de Cervantes y su obra, están formuladas desde la supuesta recuperación de la cordura por parte de Alonso Quijano antes de su muerte y del arrepentimiento de su pasado como caballero andante:

"Yo tengo juicio ya libre y claro, sin las sombras caliginosas de la ignorancia que sobre él me pusieron mi amarga y continua leyenda de los detestables libros de las caballerías."(II, 74; 1217)

"Yo fui loco y ya soy cuerdo; fui don Quijote de la Mancha y soy agora, como he dicho, Alonso Quijano el Bueno." (II, 74; 1220)

Ahora bien, no se ha de olvidar y debemos de tener siempre presente el tono festivo e irónico constante en todo el libro, y nos preguntamos con Juan Fernández Jiménez ¿por qué este capítulo debe ser distinto? "Simply because it speaks of death, that most important event, we can not forget the festive and ironic tone that is ever present in Don Quixote. Why should this chapter be different?"14 Efectivamente, un análisis desde el punto de vista de la duda y de la ironía ${ }^{15}$ de la recuperación de la cordura por parte de don Quijote nos da

7. Avalle-Arce, Juan Bautista, Don Quijote como forma de vida, Madrid, Castalia, 1976, p. 108

8. CASAlduERO, Joaquín, "La composición del segundo Quijote", Realidad 2, 1947, p. 218.

9. ZIOMEK, Henryk, "La actitud de Cervantes ante la muerte en el Quijote", Duquesne Hispanic Review 1,1969 , p. 22.

10. IfFland, James, “ Don Francisco, Don Miguel y Don Quijote: Un personaje en busca de su testamento.” Edad de Oro XII, 1994, p. 79.

11. Murillo, Luis Andrés, A Critical Introduction to Don Quixote, New York, Peter Lang, 1988, p. 216.

12. SÁNCHEZ, Alberto, "Arquitectura y dignidad moral de la segunda Parte del Quijote", Anales Cervantinos XVIII ,1979-80, p. 23.

13. RodríGuez, Juliá Edgardo, "El final del Quijote”, La Cervantiada. Madrid, Ediciones Libertarias, 1993, p. 199.

14. JIMÉNEZ, Juan Fernández, “Anticipation and meaning in Don Quixote's death", Indiana Journal of Hispanic Literatures 5, 1994, p. 84.

15. Bien apunta Leland Chambers al comentar que: "the most ironic result of Alonso Quijano's new clarity of mind is a rash gesture of a piece with all his actions as a knight." CHAMBERs, Leland $\mathrm{H}$, "Irony in the final chapter of the Quijote", The Romanic Review LXI 1970, p. 20. 
otra lectura distinta y, al mismo tiempo, creo que más coherente con el personaje cervantino, con su ser (Alonso Quijano) con su vivir (don Quijote) y en su morir (Alonso Quijano el Bueno).

Recapitulemos. Don Quijote regresa a su aldea tras haber sufrido humillación tras humillación; confundido desde el encantamiento de Dulcinea, desilusionado por los acontecimientos -vividos, inventados o soñados- ocurridos en la Cueva de Montesinos, ridiculizado en el palacio de los Duques, desprestigiado en Barcelona y, finalmente, derrotado por el Caballero de la Blanca Luna en las playas de la ciudad Condal. Ya en palabras del hidalgo manchego: "Pero ¿qué digo, miserable? ¿No soy yo el vencido? ¿No soy yo el derribado? ¿No soy yo el que no puede tomar arma en un año? Pues ¿qué prometo? ¿De qué me alabo, si antes me conviene usar de la rueca que de la espada?" (II, 65; 1164) Don Quijote tiene ante sí un futuro bastante desolador: su dama encantada, y con los augurios que no la volverá a ver, sin su biblioteca, sin sus sueños y, sobre todo, sin su libertad de leer el mundo. Ante esta perspectiva ¿qué salida digna de un caballero andante le queda a nuestro héroe? La misma que la de los mártires de Numancia de Cervantes: "En términos nos tiene nuestra suerte,/ dulces amigos, que sería ventura/ de acabar nuestros días con la muerte" (vv. 1233-1235).

Nuestro hidalgo ya no piensa en cómo vivir, sino en cómo morir ${ }^{16}$. Una muerte cristiana con testamento y confesión al modo que aconsejaba Erasmo en su Preparatio ad morte (1534). Según Pierre-Emmanuel Dauzat, haciendo referencia a otro opúsculo del humanista holandés en torno a la muerte, Dispuntaincula de taedio, pavore, tristilia Jesu, instante supplicio Via (1499), la tristeza final de Cristo se debía a un deseo de "entrar en acción", de entregarse a la muerte, de ver en ella el único medio para salvaguardar en sí un ideal trascendente, redentor ${ }^{17}$. En similar situación se encuentra el caballero andante, por eso Don Quijote no se muere, "se deja morir" y la razón no es otra que una "tristeza grande y permanente y hace que el que la padece no halle gusto ni diversión en cosa" (así define el Diccionario de Autoridades a la melancolía). El hidalgo manchego está contagiado de esa enfermedad que los latinos

16. Veamos en un ejemplo de Tirante el Blanco con que dignidad deben de morir los caballeros andantes:

"Yo quiero usar contigo desta manera [la misericordia] que tú as usado con los otros -dixo Tirante- por tu mucha virtud y bondad. Vamos delante del Rey, e allí, puesto de rodillas a mis pies, pidirme as merced, e yo perdonarte he liberalmente.

-No plega a Dios ni me dé poder que en tanto que biviere haga acto de tanta vergüença para mí ...Por tanto, haz de mi lo que fuere tu voluntad, que más quiero buena muerte que deshonrada vida."

"Los juezes de campo eran doze: los seys tenían un libro de los vencedores, los otros tenían otro de los vencidos; aquellos que morían sin se desdezir hazíanles historia de mártyres de armas; a los que se desdizían hazíanles historia de malos cavalleros vencidos, diziéndoles injurias e infamias, y aquesta orden han guardado hasta el fin." Cito por la edición de RIQUER, Martín de, Tirante el Blanco, Madrid, Espasa-Calpe, 1974, p. 174.

17. Citado en el excelente libro de ANDRÉs, Ramón, Historia del suicidio en Occidente, Barcelona, Ediciones Península, 2003. 
llamaron taedium vitae : "Fue el parecer del médico que melancolías y desabrimientos le acababan." (II, 74; 1216) Sancho, su escudero, su amigo, entendió mejor que nadie las razones de la muerte de su amo:

\footnotetext{
“-¡Ay! -respondió Sancho llorando-. No se muera vuestra merced, señor mío, sino tome mi consejo, y viva muchos años; porque la mayor locura que puede hacer un hombre en esta vida es dejarse morir, sin más ni más, sin que nadie le mate, ni otras manos le acaben que las de la melancolía." (II, 74; 1219)
}

Recordemos que las primeras muertes en el Quijote son, también, muertes por melancolía ${ }^{18}$ : Guillermo, el padre de Marcela, muere "De pesar de la muerte de tan buena mujer murió su marido" (I, 12; 131) y Grisóstomo el melancólico muere desesperado "de amores." Don Quijote se muere, usando la hermosa definición con que Erwin Panofsky describe la actitud del Ángel de la Melancolía de Durero, por "la inercia de un ser que renuncia a lo que está a su alcance porque no puede alcanzar lo que anhela"19: Dulcinea.

Dulcinea es la mujer ideal que alaba con devoción don Quijote, la encarnación misma de sus sueños caballerescos; pero su dama, como sabemos, no es una realidad, sino una representación idealizada. Por lo tanto, no podría ser más que una ficción. Ella simboliza la misión que él se impone. Por muy absurda y extremada que se conciba dicha misión, sigue siendo algo por lo que vivir, que justifica su existencia ante sí mismo: "vénganse [los encantadores] en las cosas que más quiero, y quieren quitarme la vida maltratando la de Dulcinea, por quien yo vivo." (II, 32; 899) Como dice Martín Morán: "Para su acción es indispensable que exista Dulcinea; es el sustento de la misma; si no creyera en Dulcinea no creería en sus acciones, porque Dulcinea es el alfa y el omega de todos los valores que él defiende, la fuerza centrípeta que ordena sus hazañas en serie única en torno a su persona y el elemento de unión entre la realidad y las ideas." 20 El único fallo en el plan de don Quijote es que no haya pensado en las limitaciones humanas, por las cuales todo su proyecto iba a enfrentarse con el desencanto.

En la segunda parte de la novela Dulcinea representa claramente ya no una idealización absurda, sino su misión. El poder recibir su aprobación sería su culminación como caballero andante, y la prueba de su existencia como tal. Al comienzo de la segunda parte anda buscándola; quiere recibir su bendición, la que solían otorgar las damas a sus sufridos amantes, pero nunca la alcanza. Sin embargo, al final todavía cabalga esperando encontrarla, y el lector puede distinguir la disminución de su autoconfianza hasta perder toda la arrogancia

18. En torno a Cervantes y la melancolía hay numerosos trabajos, véase una amplia bibliografía en GiberT, Javier García, Cervantes y la Melancolía, Valencia, Edicions Alfons el Magnànim, 1997.

19. PONOFSKy, Erwin, Vida y arte de Alberto Durero, Madrid, Alianza Forma, 1982, p. 183.

20. MARTín MORÁN, José Manuel, El Quijote en ciernes, Turín, Edizioni dell'Orso, 1990, p. 30. 
Episodio lleno de símbolos como ya notó E. C. Riley: "In the first place, the length and the amount of detail in the incident are disproportionate ... Cervantes makes enough signals to alert us to the possibility that these omens may be more interest than Sancho and most commentators have appeared to think"22. Cuánta razón llevaba el desaparecido maestro. El augurio es poco propicio. De hecho, pone punto final al sueño de ver a su dama. Su amor ideal resulta ser una liebre temblorosa perseguida por galgos. Cansado y melancólico se retira a su lecho para nunca más volver a levantarse. El amor ideal es una ilusión; una ilusión vital ya perdida. No hay razón para seguir viviendo, porque : "el caballero andante sin dama es como el árbol sin hojas, el edificio sin cimiento, y la sombra sin cuerpo de quien se cause." (II, 32; 897)

Pero Cervantes, naturalmente, no puede enterrar a su héroe sin un guiño burlesco al lector: me refiero al testamento de don Quijote : a la ama le paga lo que le debe "más veinte ducados para un vestido," un detalle simpático pero no muy generoso. A la sobrina le deja toda la hacienda, pero la condena a la soltería o a la pobreza: "es mi voluntad que si Antonia Quijana, mi sobrina, quisiere casarse, se case con hombre de quien primero se haya hecho información que no sabe qué cosa sean libros de caballerías; y en caso que se averiguare que lo sabe, y, con todo eso, mi sobrina quisiere casarse con él, y se casare, pierda todo lo que he mandado." (II, 74; 1220) Con Sancho Panza quiere cerrar un contrato, una deuda, que tiene pendiente: "es mi voluntad que de ciertos dineros que Sancho Panza, a quien en mi locura hice mi escudero, tiene, que porque ha habido entre él y mí ciertas cuentas, y dares y tomares, quiero que no se haga carga dellos, ni se le pida cuenta alguna, sino que si sobrare alguno después de haberse pagado de lo que le debo, el restante sea suyo." (II, 74; 1219) ¿Cuál es esta cuenta que tienen sin saldar caballero y escudero? No es otra que el desencantamiento de Dulcinea: "De mí te sé decir que si quisieras paga por los azotes del desencanto de Dulcinea, ... me parece que no se perderá nada en probarlo: mira, Sancho, el que quieres, y azótate luego, y págate de contado y de tu propia mano, pues tienes dineros míos." (II, 71; 1199)

Recordemos, y no es por casualidad, que fue el propio Sancho quien deshizo los augurios a la entrada de la aldea:

-Estraño es vuesa merced -dijo Sancho-. Presupongamos que esta liebre es Dulcinea del Toboso y estos galgos que la persiguen son los malandrines encantadores que la trasformaron en labradora; ella huye, yo la cojo y la pongo en poder de vuesa merced, que la tiene en sus brazos y la regala: ¿qué mala señal es ésta, ni qué mal agüero se puede tomar aquí?

Los dos mochachos de la pendencia se llegaron a ver la liebre, y al uno dellos preguntó Sancho que por qué reñían; y fuele respondido por el que había dicho «no la verás más en toda tu vida», que él había tomado al otro

22. RILEY, Edward C. "Symbolism in Don Quixote, Part II, Chapter 73” JHP, 3, 1979, pp. 161-174.

ANALES CERVANTINOS, VOL. XXXVII, PP. 179-190, 2005. ISSN: 0569-9878 
que tuviera en la primera parte, donde se mostraba seguro de que Dulcinea existía y era alcanzable. El episodio de la Cueva de Montesinos, cuando baja al mundo de los sueños, nos muestra sus temores respecto a la verdadera existencia de su amada. En el sueño no es nada heroico. Al contrario, nos encontramos con un caballero viejo y cansado, en una atmósfera sumamente melancólica. Cuando aparece Dulcinea la ve encantada y de mal parecer. Trata de hablarle pero ella no le contesta; le da la espalda y huye corriendo fuera del alcance de su vista. Poco después viene su sirvienta y le dice que Dulcinea está pasando grandes estrecheces económicas y le pide como préstamo seis reales. Don Quijote no le puede conceder este pequeño favor porque sólo tiene cuatro. El caballero no puede darle a su dama una ridícula cantidad de dinero, es incapaz de ayudarla en lo más mínimo. El ideal queda destruido; ha germinado en don Quijote la semilla de la desilusion.

Más tarde, cuando don Quijote está entrando a su vieja aldea, espera poder verla en cualquier momento y sucede entonces uno de los episodios más conmovedores de todo el libro:

A la entrada del cual, según dice Cide Hamete, vio don Quijote que en las eras del lugar estaban riñendo dos mochachos, y el uno dijo al otro:

-No te canses, Periquillo, que no la has de ver en todos los días de tu vida.

Oyólo don Quijote, y dijo a Sancho:

- ¿No adviertes, amigo, lo que aquel mochacho ha dicho: «no la has de ver en todos los días de tu vida»?

-Pues bien, ¿qué importa -respondió Sancho- que haya dicho eso el mochacho?

-¿Qué? -replicó don Quijote- ¿No vees tú que aplicando aquella palabra a mi intención, quiere significar que no tengo de ver más a Dulcinea?

Queríale responder Sancho, cuando se lo estorbó ver que por aquella campaña venía huyendo una liebre, seguida de muchos galgos y cazadores, la cual, temerosa, se vino a recoger y a agazapar delante de los pies del rucio. Cogióla Sancho a mano salva y presentósela a don Quijote, el cual estaba diciendo:

-Malum signum! Malum signum! Liebre huye; galgos la siguen: ¡Dulcinea no parece! (II, 73; 1210) 21

21. Ya encontramos en La Galatea libro I un claro precedente de este episodio: "A este punto del cuento de sus amores llegava Theolinda, quando los pastores sintieron grandísimo estruendo de vozes de pastores y ladridos de perros, ... Y assí vieron que por un verde llano que a su mano derecha estava, atravessavan una multitud de perros, los quales venían siguiendo una temorosa liebre, ... Y no tardó mucho que por el mesmo lugar donde las pastoras estavan, la vieron entrar y irse derecha al lado de Galatea, ... mas Galatea, tomando la temorosa liebre en los braços, estorvó su vengativo intento a los cobdiciosos perros, por parecerle no ser bien si dexava de defender a quien della havia querido valerse". Cito por la edición de Avalle-ArCE, Juan Bautista, La Galatea, Madrid: Espasa-Calpe, 1987, pp. 119-120. 
mochacho una jaula de grillos, la cual no pensaba volvérsela en toda su vida. Sacó Sancho cuatro cuartos de la faltriquera, y dióselos al mochacho por la jaula, y púsosela en las manos a don Quijote, diciendo:

-He aquí, señor, rompidos y desbaratados estos agüeros, (II, 73; 1211).

Tampoco debemos de olvidar que don Quijote, incluso con la lanza del Caballero de la Blanca Luna sobre su visera, renuncia a todo excepto a su dama: "-Dulcinea del Toboso es la más hermosa mujer del mundo, y yo el más desdichado caballero andante de la tierra, y no es bien que mi flaqueza defraude esta verdad. Aprieta, caballero, la lanza, y quítame la vida, pues me has quitado la honra." (II, 64; 1160) Añade E. C. Riley "But it is evident that Quixote's interpretation is incomplete, for how can one ignore the fact that it comes to rest under Sancho's donkey? Sancho then completes the symbolic event by handing over the hare to Don Quixote. ... His clear intentation is to change the sense of this omen for his master too"23.

Quevedo, al escribir su propia interpretación del testamento de don Quijote, fue el primero en ver lo poco cuerdo que es el personaje cervantino autor de este testamento:

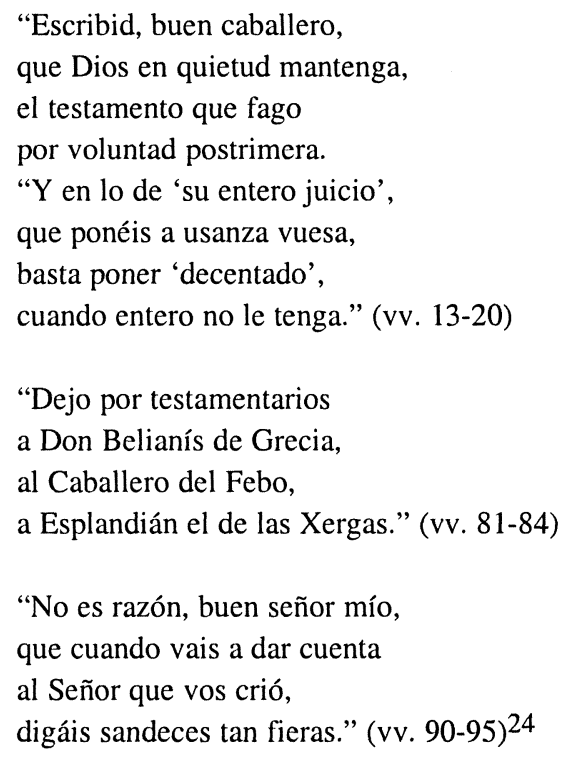

24. Cito por la edición de Blecua, José Manuel, Francisco de Quevedo, Obra Poética, Madrid, Castalia, 1970. "El Testamento de Don Quijote" Vol II. En torno a la polémica sobre si Quevedo escribió su romance basándose o inspirándose en el Quijote de 1605 o 1615 véase el trabajo de James IFFLAND, Op. cit. 
Ya Stephen Gilman insinuaba que "Quevedo tuvo cuidado de conservar el valor del héroe e insistir en él. Fue allí donde se dio cuenta de que había una significación por debajo de la superficie."25 Significación que no pasó desapercibida a los ojos de Alberto Sánchez: "Parodia de una parodia viene a ser la composición quevedesca; o mejor dicho, la caricatura de una parodia."26

Pero esto no es todo. ¿Es cosa de cuerdos el despertarse y de buenas a primeras proclamar: "Dadme albricias, buenos señores, de que ya yo no soy don Quijote de la Mancha, sino Alonso Quijano, a quien mis costumbres me dieron renombre de "bueno'" (II, 74; 1217)? ¿Y que el mismo fervor, entusiasmo y voluntad hacia el ideal caballeresco se convierta ahora en rechazo y arrepentimiento? Pura pantomima. Bien señalan, entre otros, Torrente Ballester, Lo Ré, Guillén y Edwin Williamson que el hidalgo nunca renuncia haber sido don Quijote ${ }^{27}$, sólo dice que ya no lo es. También, el narrador hace caso omiso al nuevo nombre y tanto en el título del capítulo como en el mismo le sigue llamando don Quijote; además, si hubo un don Quijote el bueno qué impide que haya un Alonso Quijano el Bueno. Álvaro Tarfe, personaje de el Quijote de Avellaneda (el Quijote malo), declara ante el alcalde que Alonso Quijano es el Quijote bueno: "los encantadores que persiguen a don Quijote el bueno han querido perseguirme a mí con don Quijote el malo." (II, 72; 1206).

La muerte de Alonso Quijano el Bueno es una representación para los espectadores de la misma: "Yo me siento sobrina, a punto de muerte; querría hacerla de tal modo, que diese a entender que no había sido tan mala, que dejase renombre de loco." (II, 74; 1217) Atina Rachel Schmidt al comentar que: "given the fact that so many intelligent readers over the course of centuries have overlooked these inconsistencies, one can only conclude that Alonso Quijano's performance has been spectaculary successful." 28 . Curiosamente, la sobrina, el ama, el barbero y el cura que anteriormente pusieron a prueba la veracidad de la recuperación de la cordura de don Quijote:

"y habló Don Quijote con tanta discreción en todas las materias que se tocaron, que los dos esaminadores creyeron indubitadamente que estaba del todo bueno y en su entero juicio.

25. Gilman, Stephen, Cervantes y Avallaneda: estudio de una imitación, México, Colegio de México, 1951, p. 77.

26. SÁNCHEZ, Alberto, Cervantes Y Quevedo: dos genios divergentes del humor hispánico, Madrid, Publicaciones del Instituto Nacional de Enseñanza Media Cervantes, 1981, p. 36.

27. "Sin embargo, [Don Quijote] sigue convencido hasta el último momento de que es posible llevar a cabo la restauración del mundo de la caballería sin haber admitido lo contario, ni puesto en duda jamás su adhesión al código caballeresco." WilLiamson, Edwin, El Quijote y los libros de caballerías, Madrid, Taurus, 1991, p. 71. Véase también TORRENTE BALLESTER, Gonzalo, El Quijote como juego, Madrid, Guadarrama, 1975. A. G. Lo Ré, "The three deaths of Don Quixote: Comments in favor of the romantic critical approach", Cervantes 9. Fall, 1989, pp. 21-41. Guillén, Jorge, "Vida y muerte de Alonso Quijano", Romanische Forschungen 64, 1952, pp.102-113.

28. SCHмIDT, Rachel, "The Performance and Hermeneutics of Death", Cervantes Fall, 2000, p. 106. 
Halláronse presentes a la plática la sobrina y ama, y no se hartaban de dar gracias a Dios de ver a su señor con tan buen entendimiento; pero el cura, mudando el propósito primero, que era no tocarle en cosa de caballerías, quiso hacer de todo en todo esperiencia si la sanidad de Don Quijote era falsa o verdadera," $(I, 1 ; 626)$.

Examen que no se repetirá en el capítulo final. Los antiguos amigos de don Quijote creen lo que quieren creer: "Miráronse unos a otros, admirados de las razones de don Quijote, y, aunque en duda, le quisieron creer." (II, 74; 1218)

La muerte de don Quijote será como fue su vida, una muerte literaria, condicionada y dictada por los libros; como señala E. Friedman "he lives on because of the book, because he has lived by the book." 29 Ahora bien, si en Sierra Morena don Quijote, para demostrar su amor a Dulcinea, tuvo dudas en imitar en su penitencia al melancólico Amadís o al colérico Orlando, decidiéndose finalmente por el primero:

“ Ya no te he dicho -respondió don Quijote- que quiero imitar a Amadís, haciendo aquí el desesperado, del sandio y del furioso, por imitar juntamente al valiente don Roldán? y así lo ha de hacer y hace el que quiere alcanzar nombre de prudente y sufrido, imitando a Ulises, ....Amadís fue el norte,...,a quien debemos imitar todos....que el caballero andante a quien más imitaré....Ansí que me es más fácil imitarle...que quiero imitar a Amadís,...por imitar al valiente don Roldán... Y, puesto que yo no pienso imitar a Roldán....contentarme con sola la imitación de Amadís."(I, 25; 275-76-77)

"Viva la memoria de Amadís, y sea imitado de don Quijote de la Mancha Ea, pues, manos a la obra: venid a mi memoria cosas de Amadís, y enseñadme por dónde tengo de comenzar a imitaros." (I, 26; 291)

¿A quién imitará en su muerte? La ignorancia del escribano nos da la clave: "Hallóse el escribano presente, y dijo que nunca había leído en ningún libro de caballerías que algún caballero andante hubiese muerto en su lecho tan sosegadamente y tan cristiano como don Quijote." (II, 74; 1221) Como antes nos la dio la sabiduría del cura en el escrutinio de la librería de don Quijote:

“i...que aquí esté Tirante el Blanco! Dádmele acá, compadre; que hago cuenta que he hallado en él un tesoro de contento y una mina de pasatiempos. ...Dígoos verdad, señor compadre, que, por su estilo, es éste el mejor libro del mundo: aquí comen los caballeros, y duermen y mueren en sus camas, y hacen testamento antes de su muerte, con estas cosas de que todos los demás libros deste género carecen.” (I, 6; 83)

29. FRIEDMAN, Edward, "Executing the will: The end of the road in Don Quixote", Indiana Journal of Hispanic Literatures 5, 1994, p. 121. 
Alonso Quijano, al transformarse en don Quijote, sólo dio pesadumbres y dolores de cabeza a su familia y a los amigos cercanos. Don Quijote se convertirá en Alonso Quijano el Bueno su nuevo heteronónimo -como antes lo fueron el Caballero de la Triste Figura, el Caballero de los Leones, entre otros- para que en encumbrado sacrificio, como lo calificó Unamuno ${ }^{30}$, hacer que renuncia a su obra y a su gloria. Bien lo nota Jaime Fernández al decir "que [don Quijote] se apropie de esa bondad para calificar su nombre, indica mucho de la fusión y de la sintonía que en él se han producido con su existencia anterior como caballero andante."31 Así, Alonso Quijano el Bueno actuará acorde y consecuentemente con su nueva personalidad, al modo de Tirante:

"-Callad, hijas -les respondió don Quijote-; que yo sé bien lo que me cumple. Llevadme al lecho, que me parece que no estoy muy bueno, y tened por cierto que, ahora sea caballero andante, o pastor por andar, no dejaré siempre de acudir a lo que hubiéredes menester, como lo veréis por la obra." (II, 73; 1215)

La obra será someterse a los deseos de quienes le rodean, honrándose con la propia muerte como en los versos del divino Herrera: “ Dio m'el cielo en destino aquesta suerte,/i yo la procuré i hallé el camino/ para poder onrarme con mi muerte." (Elegía III, vv.63-65) y arreglando sus asuntos espirituales con la Iglesia y los terrenales con el Estado : "tráiganme un confesor que me confiese y un escribano que haga mi testamento." (II, 74; 1218) Como antes había hecho su modelo: "Entonces Tirante se tuvo por muerto y mandó que llamasen a su confesor... Como ovieron hecho lo que cumple al ánima, hizo llamar a su secretario y ordenó su testamento." (V, 184-85) Pero Alonso Quijano no puede subsistir sin don Quijote, son como la pluma y el personaje: "solos los dos somos para en uno, a despecho y pesar del escritor fingido" (II, 74; 1223). Hannah Arendt ya señaló que el aislamiento, la impotencia y la capacidad de actuar del individuo se manifiesta más abiertamente cuando mayor es la presión social: "En la vida solitaria ... yo soy por mí mismo. Junto con mi yo, y por eso somos dos en uno, mientras que en la soledad yo soy realmente uno, abandonado de todos los demás"32. Para M. Blanchot eso supone una soberanía sobre sí mismo, un alcanzarse, "sin embargo quien es alcanzado no es más yo, es otro, de modo que cuando me doy muerte, tal vez sea 'yo' quien la da, pero no soy yo quien la recibe" 33 . La ama, la sobrina, el barbero, el cura y Sansón Carrasco que no entendieron, o no supieron ver que Alonso Quijano ya no existe sin su ideal: don Quijote. Ahí el detalle cruel de Cervantes para con ellos:

30. Unamuno, Miguel de, Vida de don Quijote y Sancho, Madrid, Espasa-Calpe, 1938

31. FERnÁndeZ, Jaime, "Muerte de Don Quijote: En torno al valor ético del personaje", Anales Cervantinos XXIII, 1985, p. 13.

32. ARENDT, Hannah, Los orígenes del totalitarismo, Barcelona, Alianza, 1998, p. 577

33. Blanchot, Maurice, El espacio literario, Barcelona, Paidos, 1992, p. 97. 
“Andaba la casa alborotada; pero, con todo, comía la sobrina, brindaba el ama, y se regocijaba Sancho Panza; que esto del heredar algo borra o templa en el heredero la memoria de la pena que es razón que deje el muerto."(II, 74; 1221)

Detalle que también encontramos en su modelo:

"Y no penséys que Ypólito [el escudero de Tirante] toviese mucho dolor, que luego que Tirante fue muerto hizo su cuenta que él sería emperador y mucho más después de la muerte del Emperador y de su hija, teniendo confiança del mucho amor que la Emperatriz le teníe, que él no dudava que le tomaríe por marido y por hijo;" $(\mathrm{V}, 214)$

Alonso Quijano -el lector de novelas de caballerías-y don Quijote de la Mancha -el sueño realizado del hidalgo manchego- fusionados y liberados en la muerte de su nueva creación: Alonso Quijano el Bueno. Bien sabía Cervantes que no hay retorno posible desde el mundo de la ficción; don Quijote de la Mancha y Alonso Quijano el Bueno morirán del mismo modo que fueron concebidos o soñados: imitando y siendo personajes de la Literatura. Irónicamente acertaron el ama y la sobrina cuando viendo dormir a su amo "más de seis horas: tanto, que pensaron que se había de quedar en el sueño". (II, 74, 1216) Ya en palabras de Borges: "El hidalgo fue un sueño de Cervantes/ y don Quijote un sueño del hidalgo./ El doble sueño los confunde y algo/ está pasando que pasó mucho antes./ Quijano duerme y sueña"34. 


\begin{abstract}
Resumen
En este artículo se estudia el ultimo capitulo de El Quijote y la supuesta recuperación de la cordura por parte del hidalgo manchego. La vida de don Quijote está condicionada por los libros, son su esencia y guía. Si su existencia está basada en la imitación a los héroes ficticios de las novelas de caballerías, también lo estará su muerte. No se ha de olvidar y debemos de tener siempre presente el tono festivo e irónico constante en todo el libro. Un análisis desde el punto de vista de la duda y de la ironía del restablecimiento del juicio por parte de don Quijote nos da otra lectura distinta y, al mismo tiempo, creo que más coherente con el personaje cervantino, con su ser (Alonso Quijano) con su vivir (don Quijote) y en su morir (Alonso Quijano el Bueno).
\end{abstract}

Palabras clave: ironía, muerte, cordura, imitación, Tirante el Blanco, testamento.

\begin{abstract}
Summary
This article focuses on the last chapter of Don Quixote and offers a different reading of and the commonly acclaimed regain of sanity of the knight-errant of La Mancha. The entire life of Don Quixote has been conditioned by books, they are his essence and his guide. If his life was but an imitation of the great fictional heroes portrayed in chivalry novels, so will his death be an imitation of the same models. It is helpful to bear in mind the constant ironic and festive tone that is predominant throughout the novel. Why should the last chapter be different? This analysis will take into consideration the tone of doubt and irony in the narration of Don Quixote's recovery of reason, and will thus offer us a different reading of the last scene, which is more coherent with the entire Cervantine character: there will be coherence of his being (Alonso Quijano), with his life (Don Quixote) and with his death (Alonso Quijano the Good).
\end{abstract}

Key words: irony, death, sanity, imitation, Tirante el Blanco, last will. 